\title{
Light-quality and -quantity effects on monoterpene-medi- ated photo-bleaching of conifer needles
}

\author{
J. Franzen ${ }^{1}$, K. Gross ${ }^{2}$, M. Bonzon ${ }^{3}$ and E. Wagner ${ }^{1}$ \\ Institutes of 1 Biology II and 2 Silviculture, University of Freiburg i.Br., F.R.G., and \\ 3 Institute of Plant Physiology, University of Geneva (CH), Switzerland
}

\section{Introduction}

In earlier publications (Wagner et al., 1987; Gross et al., 1988) we showed that monoterpenes, the characteristic products of secondary metabolism in conifers, could play a role in forest decline.

Monoterpenes are synthesized in leucoplasts at the basis of needles and are transported into resin ducts where they are kept strictly separated from the cytoplasm (Carde et al., 1980; Gleizes et al., 1983). In a working hypothesis (Wagner et al., 1987), we suggested that changes in membrane structure by air pollutants could liberate the monoterpenes from their storage compartments. In a kind of autocatalytic fashion, the thus liberated monoterpenes can induce further changes in membrane structure which can influence the membrane-bound electron transport. The inhibition of respiration and photosynthesis by the monoterpene $\beta$-pinene had been demonstrated earlier (Douce et al., 1978; Pauly et al., 1981). The inhibition of photosynthesis depends upon light intensity and probably results from an overproduction of oxygen free radicals due to monoterpene-mediated changes of membranes. The result is a photooxidative bleaching of the chloroplast pigments.

In simulation experiments, we demonstrated such monoterpene effects (Gross et al., 1988): fumigation of spruce (Picea abies (L.) Karst.) seedlings and young plants with $\beta$-pinene resulted in a monoterpene concentration- and photofluencydependent destruction of chloroplast pigments resembling the phenomenon of 'montane yellowing'. With the experiments presented here, we investigate the influence of light quality on monoterpene-mediated photo-bleaching of chloroplast pigments and on the levels of $\alpha$-tocopherol.

\section{Materials and Methods}

In the various fumigation experiments, 3 mo old spruce seedlings were incubated in glass vessels with $100 \mu \mathrm{l}$ of $\beta$-pinene per I of air. This concentration of monoterpene is comparable to the levels stored in needles (see Schönwitz et al., 1987). In parallel to each fumigation experiment, a non-fumigated control was analyzed.

Prior to the experimental treatments, the seedlings had been cultivated in groups of 50 
on a 3:1 mixture of quartzsand and vermiculite irrigated with tap water. Cultivation took place in glass vessels in continuous white light 116 $\mathrm{W} / \mathrm{m}^{2}$ ). The incubators were placed for $48 \mathrm{~h}$ in the various light environments in continuous light or in 12:12 $h$ cycles of light and dark at $298^{\circ} \mathrm{K}$. After fumigation, 5 seedlings were combined for each sample and analyzed for their pigment content and $\alpha$-tocopherol levels.

Pigment determination was carried out in acetone according to Lichtenthaler (1987). Tocopherol was extracted in $n$-hexane and quantified by HPLC on a Lichrosorb Si $60.5 \mu$ column with $n$-hexane and $3 \%$ ethylacetate.

\section{Results and Discussion}

The results are summarized in Table I. The data on the non-fumigated seedlings show a light-dependent accumulation of pigments, a well-known physiological adaptation (for review see Voskresenzkaya, 1988).

In white light/dark cycles, chlorophyll b and carotenoids were increased over the dark controls, while blue, red and far-red light conditions also led to higher levels of chlorophyll a. The increase in red light was less than in blue or in far-red light (cf. Kasemir and Mohr, 1981). High intensity white light given in light/dark cycles did not favor pigment accumulation, possibly indicative of light 'stress' (Wild, 1988), since seedlings were grown at lower light intensity prior to the experimental treatment. Photodestruction of pigments primarily affected chlorophyll a. Accumulation of chlorophyll b depended strongly upon membrane biogenesis. Grana development in conifers was also stimulated by far-red light (Tyskiewicz et al., 1979). Light

Table I. Fumigation of spruce seedlings with $\beta$-pinene (100 $\mu \mathrm{l} / \mathrm{l}$ air) for $48 \mathrm{~h}$ under various light conditions.

\begin{tabular}{lcllllll}
\hline $\begin{array}{l}\text { Light } \\
\text { cond. }\end{array}$ & $\begin{array}{l}c h / a \\
(\mu g / g)\end{array}$ & $\begin{array}{l}c h l b \\
(\mu g / g)\end{array}$ & $\begin{array}{l}c h l a+b \\
(\mu g / g)\end{array}$ & $\begin{array}{l}c a r \\
(\mu g / g)\end{array}$ & $\begin{array}{l}\text { toc } \\
(\mu g / g)\end{array}$ & $\begin{array}{l}c h l a / \\
c h l b\end{array}$ & $\begin{array}{l}c h l a / b \\
c a r\end{array}$ \\
\hline D & 991 & 357 & 1347 & 336 & 62.70 & 2.78 & 4.01 \\
& 990 & 438 & 1428 & 365 & 55.60 & 2.31 & 3.92 \\
WL/D & 996 & 390 & 1386 & 382 & 54.39 & 2.58 & 3.63 \\
& 1193 & 470 & 1662 & 438 & 56.35 & 2.56 & 3.78 \\
wL & 1169 & 394 & 1562 & 490 & 80.32 & 2.97 & 3.19 \\
& 723 & 290 & 1013 & 358 & 25.57 & 2.50 & 2.84 \\
WL/D & 922 & 377 & 1299 & 374 & 59.43 & 2.50 & 3.47 \\
& 534 & 134 & 667 & 132 & 10.30 & 4.01 & 5.08 \\
BL & 1210 & 397 & 1607 & 495 & 74.84 & 3.07 & 3.26 \\
& 993 & 364 & 1356 & 359 & 76.09 & 2.73 & 3.98 \\
bLD & 1050 & 358 & 1408 & 351 & 45.65 & 2.94 & 4.01 \\
& 1077 & 451 & 1528 & 389 & 47.39 & 2.42 & 3.92 \\
rL/D & 1037 & 354 & 1391 & 337 & 45.62 & 2.93 & 4.12 \\
& 1212 & 450 & 1662 & 423 & 62.53 & 2.70 & 3.93 \\
RL & 1092 & 352 & 1445 & 445 & 71.06 & 3.10 & 3.25 \\
& 1003 & 436 & 1440 & 486 & 92.14 & 2.33 & 2.95 \\
fr/D & 1160 & 418 & 1578 & 395 & 54.29 & 2.78 & 4.00 \\
& 1069 & 441 & 1509 & 384 & 65.26 & 2.45 & 3.94 \\
\hline
\end{tabular}

Changes in the contents ( $\mu \mathrm{g} / \mathrm{g}$ fresh weight) of chlorophylls (chl a, chl b), carotenoids (car) and $\alpha$-tocopherol (toc). Control values in italics, pinene treatment bold. $D=$ dark, $L / D=$ light/dark cycles $(12: 12 \mathrm{~h})$, white light $\left(16.2 \mathrm{~W} / \mathrm{m}^{2}\right)=$ $\mathrm{WL},\left(37.2 \mathrm{~W} / \mathrm{m}^{2}\right)=\mathrm{WL}$; blue light $\left(9.62 \mathrm{~W} / \mathrm{m}^{2}\right)=\mathrm{bL},\left(18 \mathrm{~W} / \mathrm{m}^{2}\right)=\mathrm{BL}$; red light $\left(0.88 \mathrm{~W} / \mathrm{m}^{2}\right)=\mathrm{rL},\left(8.8 \mathrm{~W} / \mathrm{m}^{2}\right)=\mathrm{RL}$; far-red light $\left(2.2 \mathrm{~W} / \mathrm{m}^{2}\right)=\mathrm{fr}$. 
quality-dependent differences in chlorophyll $b$ accumulation might result from differences in membrane biogenesis also dependent upon light quality. Earlier screening experiments indicated an increase in pigment content of chloroplasts after sublethal treatments with $\beta$-pinene in white light/dark cycles.

Depending upon light-quality, -quantity and light/dark cycles, the fumigation with $\beta$-pinene modified pigment and $\alpha$-tocopherol levels (Table I). Fumigation with $\beta$-pinene led to an increase in chl $b$ and car in (D), (wLD), (rLD) and (bLD). However, in $(w L),(W L D)$ and $(B L), \beta$-pinene strongly reduced pigment levels. The increase of pigment content with $\beta$-pinene fumigation might indicate the triggering of anti-oxidant defense mechanisms. Reduction in pigment content with $\beta$-pinene fumigation occurred under conditions of light 'stress'. As shown earlier (Gross et al., 1988), this effect correlated positively with the $\beta$ pinene concentration. Fumigation with $\beta$ pinene reduced the level of $\alpha$-tocopherol in the dark controls (D). Low intensity of white light (wL), red light (rLD, RL) and far-red light (fr/D) increased $\alpha$-tocopherol levels. Under conditions of $\beta$-pinenemediated reduction of pigment contents, $\alpha$-tocopherol levels were also strongly reduced (wL, WL/D). These results indicate differential modulation of $\alpha$-tocopherol synthesis and turnover by different photoreceptor systems and require further detailed investigations.

\section{Acknowledgments}

This work was supported by the Bundesministerium für Forschung und Technologie (contract no. 0339214A4) and F. Hoffmann-La Roche \& $\mathrm{Co}$. The responsibility for the contents rests with the authors. We are indebted to Mrs. B. Rossi for her technical help with the determination of tocopherol.

\section{References}

Carde J.P., Bernard-Dagan C. \& Gleizes M. (1980) Membrane systems involved in synthesis and transport of monoterpene hydrocarbons in pine leaves. In: Biogenesis and Function of Plant Lipids. (Mazliak P., Benveniste P., Costes C. \& Douce R., eds.), Biochemical Press, Amsterdam, pp. 441-444

Douce R., Neuburger M., Bligny R. \& Pauly G. (1978) Effects of $\beta$-pinene on the oxidative properties of purified intact plant mitochondria. In: Plant Mitochondria. (Ducet G. \& Lance C., eds.), Biochemical Press, Amsterdam, pp. 207-214

Gleizes M., Pauly G., Carde J.P., Marpeau A. \& Bernard-Dagan C. (1983) Monoterpene hydrocarbon biosynthesis by isolated leucoplasts of Citrofortunella mitis. Planta 159, 373-381

Gross K., Vollbrecht P., Franzen, J., Dietz J. \& Wagner E. (1988) Untersuchungen zum mechanismus der neuartigen waldschäden: hemmung der photosynthese und vergilbung von fichtenkeimlingen und -jungpflanzen durch begasung mit $\beta$-pinen. Allg. Forst Jagdz. 159, 45-49

Kasemir H. \& Mohr H. (1981) The involvement of phytochrome in controlling chlorophyll and 5aminolevulinate formation in a gymnosperm seedling (Pinus sylvestris). Planta 152, 369

Lichtenthaler H.K. (1987) Chlorophylls and carotenoids: pigments of photosynthetic biomembranes. Methods Enzymol. 148, 350-382

Pauly G., Douce R. \& Carde J.P. (1981) Effects of $\beta$-pinene on spinach chloroplast photosynthesis. Z. Pflanzenphysiol. 104, 199-206

Schönwitz R., Merk L. \& Ziegler A. (1987) Naturally occurring monoterpenoids in needles of Picea abies L. Karst. Trees 1, 88-93

Tyszkiewicz E., Nicolic D., Popovic R. \& Saric M. (1979) Photophosphorylation and ultrastructural development in Pinus nigra chloroplasts, grown under different spectral composition of light. Physiol. Plant. 46, 324-329

Voskresenzkaya N.P. (1988) Photoregulatory reactions and activity of the photosynthetic apparatus. Sov. Plant Physiol. 34, 538-550

Wagner E., Vollbrecht P., Janistyn B., Gross K. \& Woerth J. (1987) Monoterpen-vermittelte zerstörung des photosyntheseapparates von waldbäumen. Allg. Forstz. 42, 705-708

Wild A. (1988) Licht als streBfaktor bei waldbăumen. Naturwiss. Rundsch. 41, 93-96 